\title{
Audit of Obstetric Medical Evacuations at Youssou Mbargane DIOP Hospital in Rufisque, Dakar-Senegal
}

\author{
Moussa Diallo*, Omar Gassama, Mame Diarra Ndiaye, Mamour Gueye, Astou Coly Niassy Diallo, \\ Aissatou Mbodji, Abdoul Aziz Diouf, Magatte Mbaye
}

Department of Obstetrics and Gynecology, National Hospital of Pikine, sis Camp Thiaroye, Dakar, Senegal

Email: *moussadiallo25@hotmail.com, magatte4@yahoo.fr

How to cite this paper: Diallo, M., Gassama, O., Ndiaye, M.D., Gueye, M., Niassy Diallo, A. C., Mbodji, A., Diouf, A.A. and Mbaye, M. (2019) Audit of Obstetric Medical Evacuations at Youssou Mbargane DIOP Hospital in Rufisque, Dakar-Senegal. Open Journal of Obstetrics and Gynecology, 9, 1092-1102.

https://doi.org/10.4236/ojog.2019.98106

Received: June 5, 2019

Accepted: August 4, 2019

Published: August 7, 2019

Copyright $\odot 2019$ by author(s) and Scientific Research Publishing Inc. This work is licensed under the Creative Commons Attribution International License (CC BY 4.0).

http://creativecommons.org/licenses/by/4.0/

\begin{abstract}
Objectives: To assess the quality of the obstetric evacuation system at the Youssou Mbargane Diop Hospital in Dakar. Methods: Our study was conducted at the Hospital of Youssou Mbargane DIOP in Rufisque, a district about $26 \mathrm{~km}$ from downtown Dakar. This was a qualitative and evaluative descriptive study in the form of operational research aimed at improving the quality of obstetrical evacuations and resolving problems through a dynamic and team approach. It was carried out within the framework of the AQUASOU project (Improvement of Quality and Access to Emergency Obstetric Care in French). A liaison sheet was completed at the arrival of each evacuated patient, prospectively during the period from December 242006 to July 10 2008. The epidemiological characteristics were, origin of the evacuated, the evacuation conditions, evacuation patterns and therapeutic data. The data were collected through an Excel database developed for this purpose. The analysis was done using the Epi-Info version 6.0 software. Results: The frequency of evacuations was $23.2 \%$. The average age of our patients was 25.3 years with extremes of 14 years and 48 years. More than half of the evacuees (59\%) came from the Sanitary District of Rufisque. The majority of evacuations were made in a taxi (76.5\%). An ambulance was used in 190 cases (20.6\%). Seated transport was performed in $78 \%$ of cases. The transfer was medicalized in almost one-third of cases (29.3\%). A liaison sheet was established during the transfer of patients in $77 \%$ of the cases. Evacuations were related to hemorrhage in $23.3 \%$, dystocia in $22.2 \%$, and fetal-adnexal anomaly in $17.3 \%$ of cases. No treatment was instituted before evacuation in $56 \%$ of evacuees. $48.5 \%$ of the evacuees had received treatment beyond. Conclusion: The poor quality of obstetric evacuations seems to be a brake on the decline in maternal and neonatal mortality in Senegal. Training and retraining of health personnel would improve maternal-fetal and neonatal morbidity and mortality.
\end{abstract}




\section{Keywords}

Obstetrical Evacuation, Morbidity, Mortality, AQUASOU

\section{Introduction}

In Senegal, in level 2 and 3 reference health facilities, a large proportion of maternal deaths are of concern to women evacuated from peripheral structures [1]. Several factors explain this: poor antenatal care, inadequate care of the parturients, the problem of the geographical accessibility of the reference centers, the lack of material, logistical and financial resources. The share of evacuation in maternal mortality and morbidity is very high. The poor quality of obstetric evacuations thus seems to represent one of the obstacles to the reduction of maternal mortality in Senegal. It is in this very complex context that the fight for the prevention of maternal mortality is carried out in Senegal; with priority now being given to emergency obstetric care. Thus, we wanted to evaluate the organization of emergency obstetric evacuations, particularly in the Sanitary District of Rufisque where the availability of Complete Obstetric and Neonatal Care (SONUC in French) became a reality since October 2005. The general objective of this work was to evaluate the quality of the obstetric evacuation system at the Youssou Mbargane Diop de Rufisque Health Center.

\section{Patients and Methods}

Our study took place at the Maternity Hospital Center Youssou Mbargane DIOP of Rufisque, district about $26 \mathrm{~km}$ from downtown Dakar. This was a qualitative and evaluative descriptive study in the form of operational research aimed at improving the quality of obstetrical evacuations and resolving problems through a dynamic and team approach. It was carried out within the framework of the AQUASOU project (Improvement of Quality and Access to Emergency Obstetric Care in French). Its objective was to contribute to the reduction of maternal mortality and morbidity in the 17 SAGO "in French" (African Society of Obstetrics and Gynecology) member countries. In Senegal, the project took place at Rufisque and Saint-Louis. In Rufisque, the project aimed to evaluate the organization of obstetric evacuations. Thus, the implementation of auditing practices appeared to be the best way to highlight and become aware of dysfunctions in this obstetric structure. For this purpose, in the Rufisque Reference Center, a liaison sheet was completed on arrival of each evacuated patient, prospectively during the period from December 24, 2010 to July 10, 2012. This sheet included data on the reason for the evacuation, the time of arrival in the peripheral structure, the time of the decision to evacuate, the time of arrival in the reference structure, the conditions of transport, the condition of the patient and the diagnosis on arrival, the outcome of the delivery. The records of the patients, the various registers and the liaison sheet had also served as a support for the completion of the audit form. Epidemiological characteristics (age, marital status, 
occupation, parity, gesture), origin of evacuees, conditions of evacuation, reasons for evacuation, treatment data (treatment before evacuation, adapted treatment, Supported, type of support). The process indicators were then measured. The data were collected using an Excel database developed for this purpose. The analysis was done using the Epi-Info version 6.0 software.

\section{Results}

\subsection{Frequency}

During the study period, we recorded 972 patients discharged out of a total of 4178 patients, a frequency of $23.2 \%$.

\subsection{Epidemiological Characteristics}

The average age of our patients was 25.3 years with extremes of 14 years and 48 years; the age group 20 to 29 was the most represented (47.9\%). Almost all patients were married (93\%). A 98\% proportion was without a profession. This situation resulted in a low socio-economic level in $99 \%$ of the cases. The average gestleness was 2.6 with extremes a primigeste and a twelfth gesture. The average parity was 1.6. Almost half of our patients had never given birth (49.2\%). The primiparae accounted for $13.5 \%$; the paucipares accounted for $18.7 \%$ and the large multiparties accounted for $6.4 \%$.

\subsection{Origin and Evacuation Conditions}

More than half of the evacuees (59\%) came from the Sanitary District of Rufisque. Those that came from a structure belonging to the Sanitary District of Rufisque were 379 , or $41 \%$ of the cases.

\subsection{Evacuation Conditions}

The majority of evacuations were made in a taxi (76.5\%). An ambulance was used during this transfer in 190 patients (20.6\%). Seated transport was performed in 78\% of cases; the transfer was medical in almost one third of cases (29.3\%). A liaison sheet was established during the transfer of patients in $77 \%$ of the cases. Table 1 shows the conditions of evacuation of the patients.

\subsection{Evacuation Grounds}

Evacuations were related to haemorrhage in $23.3 \%$ (226), dystocia in $22.2 \%$ (215), and fetal-adnexal abnormality in $17.3 \%$ (168) of cases as shown in Table 2. In addition to these purely clinical evacuation grounds, there were other material reasons. It was a lack of space, or a lack of consumables (surgical drapes, sterile coats and sterile materials).

\subsection{Therapeutic Data}

\subsubsection{Treatment Received Prior to Evacuation}

No treatment was instituted before evacuation in $56 \%$ of evacuees. On the other hand, $44 \%$ of the patients ( 405 cases) received treatment before or during their 
Table 1. Distribution of patients by evacuation conditions.

\begin{tabular}{ccc}
\hline Means used & Effective & Percentage \\
\hline Taxi & 744 & 76.6 \\
Ambulance & 201 & 20.6 \\
Private car & 23 & 2.4 \\
Bus & 2 & 0.2 \\
Other & 2 & 0.2 \\
\hline Evacuation position & & \\
\hline Sitting position & 758 & 78 \\
Lying down position & 214 & 22 \\
\hline Medicalization of the transfer & & 29.3 \\
\hline Medical transport & 285 & 70.7 \\
\hline Unscheduled transport & 687 & \\
\hline Establishment of a transfer form & & 77 \\
\hline With transfer form & 748 & 23 \\
Without transfer form & 224 &
\end{tabular}

Table 2. Distribution of patients by reason for evacuation.

\begin{tabular}{ccc}
\hline Reasons for evacuation & Effective & Percentage (\%) \\
\hline Hemorrhages & 215 & 23.3 \\
Dystocias & 205 & 22.2 \\
Fetal-Annexal Abnormalities & 160 & 17.3 \\
Vascular renal syndromes & 108 & 11.7 \\
Excessive uterine height & 70 & 7.6 \\
Other pathologies associated with pregnancy & 30 & 3.3 \\
Other reasons for evacuation & 46 & 5 \\
Unspecified reasons for evacuation & 88 & 9.6 \\
Total Total & 922 & 100 \\
\hline
\end{tabular}

transfer to the Rufisque Health Center. This treatment was adapted only for 50\% of evacuees treated before the evacuation process.

\subsubsection{Type of Management}

Time to take care of $48.5 \%$ of the evacuees had received treatment beyond two hours after the emergency had been detected, while 83 (9\%) had received treatment within one hour of the evacuation decision. For $23.3 \%$ of patients, this period was not specified.

\subsubsection{Type of Support}

This was a natural delivery in 405 patients (43.9\%), caesarean section in $237 \mathrm{pa}$ tients (25.7\%), and manual intrauterine aspiration in 96 patients (10.4\% of cases) (Table 3). 
Table 3. Distribution of evacuations by birth route and pregnancy outcome.

\begin{tabular}{ccc}
\hline Outcome of pregnancy and route of delivery & Effective & Percentage (\%) \\
\hline Natural childbirth & 405 & 43.9 \\
Forceps & 12 & 1.3 \\
Suction cup & 39 & 4.2 \\
Caesarean section & 235 & 25.7 \\
Uterine aspiration & 96 & 10.4 \\
Digital uterine cleaning up & 39 & 4.2 \\
Expulsion & 9 & 1.0 \\
Laparotomy & 8 & 0.8 \\
Others & 59 & 6.4 \\
Total & 922 & 100 \\
\hline
\end{tabular}

\subsection{Maternal and Fetal Prognosis}

\subsubsection{Maternal Prognosis}

Nine cases of death were recorded during this period among the evacuated patients representing $1 \%$ of the cases. Direct causes of death were mainly dominated by haemorrhagic causes in 66.7\%: three (03) cases of haemorrhagic shock, two (02) cases of haemorrhage of delivery, a case of uterine rupture. Indirect causes of maternal deaths were reported in $33.3 \%$ of cases. It was mainly decompensated anemia. Apart from the 9 patients who died, only one case of complication was observed to the type of eclampsia. The majority of our patients ( $98.9 \%$ of cases) were discharged without complications.

\subsubsection{Fetal and Neonatal Prognosis}

There were 619 live births (85.3\%) and 106 stillbirths (14.7\%) with 22 stillbirths and 84 stillbirths. Stillbirths were 171 per 1000 live births. Among live births, infants with an Apgar score of $\leq 7$ in the fifth minute accounted for $77 \%$. On the other hand, the Apgar score was $>7$ at the fifth minute in 169 cases, i.e. $22.9 \%$ of live births.

\section{Discussion}

\subsection{Socio-Demographic Characteristics}

In our study, the mean age was 25.3 years. This relatively young age is related to the precocity of maternity in Africa. The mean age found was higher than that recorded by Cissé [2] and Sépou [3], who were 23.5 and 24 years old respectively. It is, however, comparable to that reported by most African authors [4] [5] [6]. The age extremes were 14 years and 48 years. These extreme ages pose a risk for pregnancy and especially during parturition. It should be noted a frequent psychological and physiological immaturity in the parturients of the young age most often expressed by a dystocia in the reasons of evacuation. The prevention of early dystocia will be difficult as long as the marriage of young nubiles re- 
mains in black Africa [7]. The need to improve family planning strategies at extreme ages is thus seen to prevent complications leading to a medical evacuation for appropriate care.

\subsection{Origin of Evacuees}

The evacuated patients from a structure belonging to the same health district accounted for $41 \%$. The importance of its evacuations within the same district is related to the absence of a technical platform adapted to the management of the operative cases at the level of the peripheral maternities. The only operating room available in this district is within the hospital which is the ultimate reference. On the other hand, patients who came from the district of Rufisque accounted for $59 \%$ of the cases. Indeed, the Hospital Center of Rufisque covered a population superior to the forecasts of the sanitary division of the pyramid. This explains the predominance of evacuations from outside the district. The Center Hospitalier contributed greatly to the decongestion of the health structures of the capital especially in terms of the management of obstetric emergencies since the closing of the Gynecological and Obstetrical Clinic of the Aristide Le Dantec Hospital for reasons of rehabilitation. This has enabled the Health Center to benefit from an adapted technical platform and qualified staff since October 2005. The geographical accessibility of the Youssou Mbargane Diop Hospital Center as well as the 24-hour availability of medical personnel justified the evacuation of patients from structures with an identical technical platform. The reasons for the evacuation were related to insufficient capacity and/or insufficient supplies essential for surgical procedures. Many obstetric complications originate from these reasons for evacuation. The need for an increase in the capacity to meet the demands of the surrounding population, but also the need for adequate supplies of products and consumables for the management of obstetric emergencies, is evident.

\subsection{Mode of Transport}

The rate of evacuated by ambulance in our study is significantly lower than that found by other authors: $64 \%$ for Coulibaly [8]; $73.8 \%$ for Diarra [7]; $98.5 \%$ for Sidibe [9]. The majority of the evacuations were made with unplanned means of transport such as a taxi $(76.6 \%)$, a personal car $(2.4 \%)$ or a bus $(0.2 \%)$. Ebene found in his study that no patient had arrived by ambulance [5]. These conditions of transport prove that evacuations are carried out under poor conditions. These logistical means are not adapted to the transfer of a pregnant woman, in labor or in the aftermath of diapers. The inadequacy of ambulances remains a problem in their own right and their availability is another. In addition, the lack of knowledge of the evacuation system and the notion of urgency and the lack of qualified personnel constitute factors which oppose quality medical evacuation, since the use of these means of transport other than the ambulance remains particularly dangerous and expensive, aggravating the materno-fetal prognosis. Only $29.3 \%$ of the evacuees had a venous route during their transport. Most pa- 
tients were evacuated without any hemodynamic assistance, a significant rate of $70.7 \%$. This rate was lower than that found by Diarra $(90,3 \%)$ [7]. The lack of venous first results in the total absence of care during an evacuation. The situation is bitter and the situation deserves special attention given the realities of today in the fight to reduce maternal and neonatal mortality. The liaison sheet is essential for understanding the history of an evacuation. It should make it possible to institute an urgent pursuit of appropriate care. In our study, $77 \%$ of the evacuees had a liaison sheet. This rate was significantly higher than that found by different authors: Diarra (19.09\%) [7], Coulibaly (29\%) [10]. This document is very important because it directs the staff of the reception center to a faster and more efficient care. The mode of evacuation is mediocre with its attendant problems aggravated by unsuitable, inappropriate logistical means; The lack first venous during transport. It is therefore urgent to ensure a quality evacuation system.

\subsection{Evacuation Grounds}

In general, the grounds for evacuation were related to obstetric emergencies. Evacuation patterns were dominated by haemorrhages (23.3\%) followed by dystocia $(22.2 \%)$ and feto-adnexal abnormalities (17.3\%). Similar reasons have been reported by Cissé [6] at the Kolda Regional Hospital with whom we share the same working conditions. At the Reference Center of Commune V of Bamako, haemorrhage, stationary dilation and arterial hypertension were recorded in $16.3 \%$, respectively; $13.5 \%$ and $8 \%$ of cases [10]. Diarra et al. [4] found that dystocia accounted for $56.2 \%$, followed by delivery haemorrhage (5.4\%) and amniotic infections (4.5\%) in their study in the Bouaflé Sanitary District of Côte d'Ivoire). At the Gynecology and Obstetrics Department of Mali-G-CHU, stationary dilation was the most common reason for evacuation with $14.3 \%$, scar uterus in 9.4\% and excessive uterine height in 7.1\% [7]. These reasons for evacuation were justified by the fact that they were most often pathologies whose management required a surgical procedure. In addition to these purely clinical reasons, there were material reasons related to the limited capacity or the lack of consumables. These motives are very often found during evacuations towards a structure of the same level, with surgical competence, institutional, administrative or organizational insufficiencies. These reasons deserve special attention from the supervisory authorities.

\section{Support}

\subsection{Treatment Received Prior to Evacuation}

Patients who received pre-evacuation treatment accounted for 56\%. Those that were evacuated without prior medication accounted for $44 \%$, thus aggravating the materno-fetal prognosis. Among the evacuees with a mention of the therapeutic received before the evacuation, the treatment was adapted only in $50 \%$ of the cases. This raises the question of the competence of the staff who decided on 
the treatment given to the patient before the evacuation. The importance of quality of care as a pillar in the reduction of maternal mortality in developing countries is now demonstrated by several studies [11] [12] [13]. As Prural notes [12], even though African countries have made considerable investments in health structures, access and quality of care are not always part of this.

\subsection{Time to Take Care}

The delays of care reported in the results. This reflects the difficulties at the different levels of the evacuation process. In Senegal, Cissé et al. [14] found in their study at the University Hospital Center A. Le Dantec that the interval between admission to the service and termination of delivery was 432 minutes. This result was different from that found by Diarra et al. for whom the take-up time was long varying from 80 minutes to $5 \mathrm{j}$ [4]. This parameter was not evaluated in $23.3 \%$ of our patients. This is a very important parameter in making certain decisions at the Reference Health Center, as the prognosis of evacuated patients may depend on it. This is in line with the classic "three delays" [15] that can explain the difficulties encountered in the care of evacuees: delay in deciding whether to use emergency care, access to the Health Center or To receive quality care once in the Center. Each of these three delays corresponds to a level of responsibility. The first case of delay is the responsibility of the family and the community. It must be recognized that certain cultural values do not encourage urgent decision-making. The explanation is to be found, among other things, in the beliefs that impose absolute discretion around pregnancy, fatality in the face of death, valorization of woman's endurance in the face of suffering and absolute search Of the husband's or mother-in-law's permission in the latter's absence. Indeed, the evacuation of a woman, even in a critical state, can be delayed for want of this permission, with consequences often fatal. Hence the importance of sensitizing the family and the community in order to predict the attitude to adopt in case of complications during the delivery or in the weeks that follow.

But one factor remains fundamental, namely the context of poverty in which these families live. Without financial means, they cannot meet the two requirements that usually accompany the use of EmOC: to pay for transportation to the health facility, and once there, to pay for the care that the evacuees will need. The second delay refers to the malfunctioning of the reference system due to poor evacuation conditions. Indeed, there is a problem in finding a suitable vehicle to evacuate the woman to the nearest structure with comfort and safety. In the context of poverty in which families and communities live, the cost of transportation, when available, does not meet the purchasing power of these. These are all factors, all of which are non-medical, but which negatively affect the survival of women by making the resolution of this problem complex. The third delay directly concerns the availability and organization of the Health Center. Indeed, the Health Center receives all the obstetric evacuations coming from the peripheral maternity hospitals thus a center of reference par excellence. However, there are certain difficulties which may affect the fate of the evacuees. Among 
them: 1) single-block accessibility requiring waiting for certain patients requiring urgent surgery; 2) the acute problem of blood transfusion: there is no functional blood bank at the Rufisque Health Center. There was a critical lack of blood, whereas in $23.3 \%$ of the evacuees the diagnosis of haemorrhage was retained; 3) lack of materials, consumables and insufficient emergency products. All these factors explain the delays in care. Efforts must be made to reduce these delays.

\subsection{Type of Support}

Medical evacuation in obstetrics is always the result of an obstetric emergency. Its therapeutic is therefore curative but would gain to become preventive at first. Our structure has used a wide range of treatments: medical, obstetrical, surgical or medico-surgical. The low-frequency pathway, comprising normal deliveries and instrumental extractions, accounted for $49.4 \%$, followed by caesarean section (25.7\%) and manual intrauterine aspiration (10.4\%). Ebène found in her study that the obstetric care of the evacuated patients was dominated by the delivery by low route $(60.5 \%)$ with use of the maneuvers in $10.8 \%$. Caesarean section was performed in $26.8 \%$ [5]. These results were different from those reported by Cissé at the Kolda Regional Hospital where caesarean section was the most common procedure with $38.1 \%$; Natural delivery was performed in $20 \%$ and instrumental maneuvers were performed in $8 \%$ of cases [2]. In Guinea Conakry [16], the evacuees, with a frequency of $41.2 \%$, were more exposed to Caesarean section with all the related risks. According to the authors [16], this finding is often related to delays in evacuation decisions, evacuation conditions and, above all, to the condition of the patients at the reception.

\section{Maternal and Fetal Prognosis}

\subsection{Maternal Prognosis}

We deplored nine deaths representing $1 \%$. The percentage of maternal deaths in our study was lower than the percentages observed in Yaoundé (1.9\%) [5]; In Bamako (2.8\%) [7]; In Burkina Faso (5.4\%) [6]. The general condition of some of the evacuees was aggravated by the difficult conditions of evacuation, the non-attendance of patients during transport, the delay in taking charge, the absence of a functioning blood bank at the level of the structure. These factors made management difficult and the maternal prognosis bad. Hemorrhage was the leading cause of maternal death in $77.7 \%$ followed by anemia $22.3 \%$. These causes of death are consistent with the data found in the literature [2] [4] [9] [10]. These maternal deaths, in most cases, had a direct obstetric cause (77.7\%) and could have been avoided if simple procedures such as venous catheterization, improved evacuation conditions were carried out. All maternal deaths could have been avoided if adequate quality care was readily available. Risk factors and difficulties that could be social, economic, cultural or related to the health system or the health of the mother could also be the cause of serious ma- 
ternal health problems or even death. To reduce risks, improvements in health systems need to be complemented by a focus on various social, economic, cultural and reproductive rights.

\subsection{Fetal and Neonatal Prognosis}

The structure did not have a neonatology unit. Manual resuscitation maneuvers allowed, in the majority of cases, to correct minor respiratory distress. A well-equipped neonatal unit would have improved the neonatal vital prognosis. Obstetrical health evacuations are a problem that challenges decision-makers about the quality of services provided at peripheral centers, often lacking in equipment and competent personnel. Harm caused by diagnostic errors, late evacuations, poor discharge conditions and delayed referral to the referral center are reflected in the already high maternal fetal mortality. The reduction of maternal and neonatal morbidity and mortality requires standardization of evacuation criteria on the basis of risk factors for the identification of pregnancies and risky deliveries, training of peripheral health personnel for recognition Of these factors, educating women about the risks they and their children face.

\section{Conclusion}

The poor quality of obstetric evacuations thus appears to be a brake on the decline in maternal and neonatal mortality in Senegal. The audit of the obstetrical evacuations made it possible to identify the flaws in the evacuation system and to provide solutions adapted to the main malfunctions in the referral system at the maternity level of the Gynecology and Obstetrics Department, Rufisque's Reference Health Center, involving the maternity units of the evacuated patients' original structures. This work showed that the audit process was feasible and could contribute to producing useful outcomes in our work context, although the experience of its practice is scarce in developing countries. This work shows that the audit of obstetrical evacuations is an activity to be integrated into our various maternity units in order to improve the management of evacuated patients, thus reducing maternal and neonatal morbidity and mortality. The recommendations emerging from this work mainly concern health personnel (training, retraining, compliance with procedures) and authorities (upgrading of premises, coordination meetings, equipment). Recommendations also apply to patients (solicit health structures to adopt preventive attitudes), leaders of community health associations and opinion leaders (raise awareness of the health evacuation difficulties, raising awareness among political authorities and opinion leaders).

\section{Conflicts of Interest}

The authors declare no conflicts of interest regarding the publication of this paper. 


\section{References}

[1] Diouf, A., Faye, E. and Diadhiou, O. (1996) Problèmes posés par les évacuations obstétricales dans un centre de référence. Quelle solution? Dakar Médical congrès communication, 96, 10-18.

[2] Cissé, M.L., Raad, B., Diouf, A., Wade, F. and Moreau, J.C. (2010) Bilan des évacuations obstétricales à l'hôpital régional de Kolda (Sénégal). Médecine d Afrique Noire, 57, 37-43.

[3] Sépou, A., Yanza, M.C. and Nguembi, E. (2000) Analyse des évacuations sanitaires en Gynécologie-Obstétrique à Bangui, Centrafrique. Cahiers d Etudes et de Recherches Francophones/ Santé, 10, 399-405.

[4] Diarra, N.A.J., Angbo, O., Koffi, M.N., et al. (1999) Morbidité et mortalité liées aux soins obstétricaux dans le district sanitaire de Bouaflé en Côte d'Ivoire. Santé Publique, 11, 193-201.

[5] Ebène, B.C. (2001) Evacuations obstétricales vers le CHU de Yaoundé. Thèse Méd., Université de Yaoundé, Yaoundé, 69 p.

[6] Lompo, K., Hutin, Y.F., Traore, G., et al. (1993) Morbidité et mortalité liées aux évacuations sanitaires d'obstétrique à l'Hôpital de Bobo-Dioulasso, Burkina Faso. Annales de la Société Belge de Médecine Tropicale, 73, 153-163.

[7] Diarra, M. (2008) Evacuations obstétricales au Service de Gynécologie Obstétrique du CHU du Point G: A propos de 682 cas. Thèse Méd., Université Bamako, Bamako, $113 \mathrm{p}$.

[8] Coulibaly, M.B. (2005) Etude des besoins obstétricaux non couverts au Centre de Santé de référence de Niono. Thèse Méd., Université de Bamako, Bamako, 122.

[9] Sidibé, I.M. (2006) Les évacuations sanitaires obstétricales au Centre de Sante de Référence de Bougouni. Etude Prospective de 2005 à 2006 à propos de 329 cas. Thèse Méd., Université de Bamako, Bamako, 92 p.

[10] Coulibaly, A.B. (2006) La référence/évacuation en Gynécologie-Obstétrique au Centre de Santé de Référence de la Commune V du District de Bamako. Thèse Méd., Université de Bamako, Bamako, 88.

[11] Fournier, P., Karl Itaj, N. and Haddad, S. (1996) La qualité des services de santé en Afrique: L'exemple du dépistage des grossesses dystociques à Nioki (Zaïre). Cah Santé, 6, 107-114.

[12] Prual, A. (1999) Grossesse et accouchement en Afrique de l'ouest: Vers une maternité à moindre risque? Santé Publique, 11, 167-185.

[13] WHO (1997) The Safe Motherhood. Action Agenda: Priorities for the Next Decade. Final Report. Colombo (Sri Lanka).

[14] Cissé, M.L., Moreau, J.C., Faye, E.H.O., Terolbe, I. and Diadhiou, F. (2002) Coût de l'évacuation des parturientes au Centre Hospitalo-universitaire Aristide Le Dantec de Dakar. Journal de la SAGO, 1, 23-27.

[15] Wane, D., Engelberg, G. and Bagdé, E. (2001) Prévention de la mortinalité maternelle par les soins obstétricaux d'urgence. Donner la vie et rester en vie. Etude des équipes des études régionales de la prise en charge des femmes en Afrique de l'ouest et du centre (Bénin, Burkina Faso, Mali, Sénégal). CEFOREP, SARA, SAGA, Dakar Sénégal.

[16] Diallo, F.B., Diallo, M.S. and Bangoura, S. (1998) Césarienne: Facteur de réduction de morbidité et de mortalité foto-maternelle. Médecine d Afrique Noire, 45, 359-364. 